\title{
Surgical resection should be taken into consideration for the treatment of small gastric gastrointestinal stromal tumors
}

\author{
Jianjun Yang ${ }^{\dagger}$, Fan Feng ${ }^{\dagger}$, Mengbin $\mathrm{Li}^{\dagger}$, Li Sun, Liu Hong, Lei Cai, Wenbin Wang, Guanghui Xu \\ and Hongwei Zhang*
}

\begin{abstract}
Background: The National Comprehensive Cancer Network (NCCN) recommends conservative follow-up for gastric gastrointestinal stromal tumors (GISTs) less than $2 \mathrm{~cm}$. The aim of the present study was to investigate the clinical and pathological features of small gastric GISTs, re-evaluate the risk potential, and discuss the treatment strategy of small gastric GISTs.

Methods: In this retrospective study, 63 cases of small gastric GISTs (less than $2 \mathrm{~cm}$ ) were resected surgically from May 2010 to March 2013 in our department. Clinicopathological factors were collected and the malignant potential of small gastric GISTs was analyzed.

Results: The mitotic index of 14 out of 63 cases (22.22\%) exceeded 5. The malignant potential of small gastric GISTs was related to tumor location ( $P=0.0218$ ). The mitotic index of 4 out of $8 \mathrm{GISTs}(50 \%)$ located in gastric cardia exceeded 5, 8 out 28 GISTs (28.57\%) located in the gastric fundus exceeded 5, and only 2 out of 27 GISTs (7.41\%) located in the gastric body exceeded 5. We also discovered a good consistency between mitotic index and Ki-67 expression of small gastric GISTs.
\end{abstract}

Conclusions: Gastric GISTs less than $2 \mathrm{~cm}$ also have malignant potential. Thus, we recommended surgical resection of all small gastric GISTs once diagnosed.

Keywords: Gastric gastrointestinal stromal tumor, Malignant potential, Mitotic index, Gene mutation

\section{Background}

Gastrointestinal stromal tumors (GISTs) are the most common mesenchymal tumor of the gastrointestinal tract and represent $1 \%$ to $2 \%$ of all gastrointestinal malignancies [1]. They are considered to be derived from the interstitial cells of Cajal, the pacemaker cells of the gastrointestinal tract [2]. This has been established by immunohistochemical staining of GISTs for CD117, CD34, smooth muscle actin, desmin and S-100 [3]. In 1998, Hirota et al. reported that GISTs are associated with gain-of-function mutations in the KIT protooncogene [2]. Histologically, most GISTs display spindle

\footnotetext{
* Correspondence: zhanghwfmmu@126.com

${ }^{\dagger}$ Equal contributors

Department of Digestive Surgery, Xijing Hospital of Digestive Diseases, the

Fourth Military Medical University, 127 West Changle Road, 710032, Xi'an, Shaanxi, China
}

(C) 2013 Yang et al.; licensee BioMed Central Ltd. This is an open access article distributed under the terms of the Creative Commons Attribution License (http://creativecommons.org/licenses/by/2.0), which permits unrestricted use, distribution, and reproduction in any medium, provided the original work is properly cited.

cell morphology $(70 \%)$, whereas a minority is of epithelioid $(20 \%)$ or mixed phenotypes (10\%) [4]. GISTs can occur anywhere throughout the gastrointestinal tract and are seen most commonly in the stomach (40 to $70 \%$ ), small intestine (20 to $40 \%$ ), and colon and rectum (5 to 15\%) [5]. Rare cases have been reported in the esophagus, appendix, greater omentum, and gallbladder [6]. Patients with gastric GISTs may be completely asymptomatic or present with abdominal pain, dyspepsia, anorexia, bleeding, obstruction or tarry stool [7].

According to the NCCN guideline [8], gastric GISTs less than $2 \mathrm{~cm}$ and with a mitotic index (number of mitoses per 50 HPF (high-power fields)) less than 5 were considered as very low risk. Thus, surgical intervention with negative margins is the treatment of choice for primary, localized gastric GISTs larger than $2 \mathrm{~cm}$, while conservative follow-up is suggested for lesions less than 
$2 \mathrm{~cm}$ [9-11]. However, it is believed that all GISTs have malignant potential [12], including small gastric GISTs (less than $2 \mathrm{~cm}$ ). To date, little is known about the natural course of small gastric GISTs, and no literature has reported the mitotic index and gene mutation spectrum of small gastric GISTs.

Given this situation, we presume that the treatment principle of gastric GISTs less than $2 \mathrm{~cm}$ should be reconsidered. In the present study, we retrospectively analyzed the clinical and pathological data of 63 patients with gastric GISTs less than $2 \mathrm{~cm}$. The aim of the present study was to reevaluate the risk potential and reconsider the treatment principle of small gastric GISTs.

\section{Methods \\ Patients}

This study was performed in the Xijing Hospital of Digestive Diseases affiliated to the Fourth Military Medical University. From May 2010 to March 2013, a total of 63 patients who were suspected of having a small gastric GIST (maximum diameter $\leq 2 \mathrm{~cm}$ ) as a result of examination by endoscopic ultrasound (EUS) and enhanced abdominal computed tomography (CT) were enrolled in the present study. Surgical resection was performed by surgeons who are specialized in gastric surgery in our department. This study was approved by the Ethics Committee of Xijing Hospital, and written informed consent was obtained from all patients before surgery.

\section{Pathology}

All the specimens were fixed in 10\% neutral formalin immediately after resection and embedded routinely for histologic examination in the Pathology Department in the Xijing Hospital. Immunohistochemistry was performed on $3-\mu \mathrm{m}$ sections according to the manufacturer's instructions and the following antibodies: CD117 (polyclonal, 1:200; DAKO, Hamburg, Germany), CD34 (clone QBEnd10, 1:200; Immunotech, Hamburg, Germany), Discovered on GIST-1 (monoclonal DOG-1, 1:200; Novocastra, Newcastle, UK), Ki67 (clone MIB1, 1:150, DAKO). Histological type (spindle, epithelioid, mixed) and mitotic index were also detected by hematoxylin and eosin stain.

\section{Gene mutation detection}

DNA of the GIST tissues was isolated using a QIAmp DNA FFPE Tissue kit according to manufacturer's instructions (Qiagen, Hilden, Germany). Polymerase chain reaction (PCR) was used to amplify KIT exons 9, 11, 13 and 17 and PDGFRA exons 12 and 18. The PCR reaction was performed using a Taq PCR Master Mix according to manufacturer's instructions (Qiagen, Hilden, Germany). Mutations were confirmed by comparing the sequencing results with gene sequences in the NCBI Genbank. Primers used in PCR were listed as follows: KIT exon 9 forward: TCCTAGAGTAGTAAGCCAGGGCTT, KIT exon 9 reverse: TGGTAGACAGAGCCTAAACATCC, KIT exon 11 forward: CCAGAGTGCTCTATAGACTG, KIT exon 11 reverse: AGCCCCTGTTTCATACTGAC, KIT exon 13 forward: GACATCAGTTTGTCAGTTG, KIT exon 13 reverse: GCAAGAGAGAACAACAG, KIT exon 17 forward: GTGA ACATCATTCAAGGCG, KIT exon 17 reverse: TTACATT ATGAAAGTCACAGG, PDGFRA exon 12 forward: TCCA GTCACTGTCCTGCTTC, PDGFRA exon 12 reverse: GCA AGGGAAAAGGGAGTCTT, PDGFRA exon 18 forward: ACCATGGATCAGCCAGTCTT, PDGFRA exon 18 reverse: TGAAGGAGGATGAGCCTGACC.

\section{Statistical analysis}

Data were processed using SPSS 16.0 for Windows (SPSS Inc., Chicago, IL, USA). Numerical variables were expressed as the mean \pm SD unless otherwise stated. Discrete variables were analyzed using the Chi-square test or Fisher's exact test. The consistency of the mitotic index and the Ki-67 was analyzed using McNemar's test and the Kappa test. The $P$ values were considered to be statistically significant at the $5 \%$ level.

\section{Results}

\section{Patient and tumor characteristics}

Clinical and pathological characteristics of the patients and tumors are summarized in Table 1. Sixty-three patients meeting the criteria for the diagnosis of EUSsuspected small gastric GISTs were enrolled, and comprised 39 men and 24 women. The average age was $62.44 \pm 9.76$ years (range: from 39 to 89 years). Approximately $73.02 \%$ of the patients were symptomatic. Presenting symptoms included abdominal pain (28.57\%), bleeding (7.94\%), and abdominal discomfort (36.51\%). On the basis of the EUS, pathology and operative report, 8 tumors were located in the cardia, 28 tumors in the gastric fundus, and 27 tumors in the gastric body. Approximately $22.22 \%$ of the patients had more than $5 \mathrm{mi}-$ totic figures per $50 \mathrm{HPF}$, and $22.22 \%$ of the patients had a positive Ki-67 stain ( $>5 \%)$. A total of 61 of the 63 cases studied (96.83\%) stained positive for CD117, 61 of the 63 cases (96.83\%) stained positive for DOG-1, and 62 of the 63 cases (98.41\%) stained positive for CD34. Molecular analysis revealed KIT exon 11 mutation in 47 cases, KIT exon 9 mutation in 3 cases, KIT exon 13 mutation in one case, KIT exon 17 mutation in one case, PDGFRA exon 18 mutation in one case, and wild type in 10 cases.

The relationship between mitotic activity and clinical features The correlations of mitotic activity and clinical features are summarized in Table 2. The results show that the mitotic index was not statistically different and had no correlations with age, sex, tumor size and clinical symptoms. However, the mitotic index was related to the location of 
Table 1 Clinical and pathological features of small gastric gastrointestinal stromal tumors (GISTs)

\begin{tabular}{|c|c|}
\hline Characteristics & Cases $(n=63)$ \\
\hline Age & $62.44 \pm 9.76$ \\
\hline \multicolumn{2}{|l|}{ Sex } \\
\hline Male & 39 \\
\hline Female & 24 \\
\hline \multicolumn{2}{|l|}{ Tumor location } \\
\hline Cardia & 8 \\
\hline Gastric fundus & 28 \\
\hline Gastric body & 27 \\
\hline \multicolumn{2}{|l|}{ Clinical symptoms } \\
\hline Pain & 18 \\
\hline Bleeding & 5 \\
\hline Discomfort & 23 \\
\hline Asymptomatic & 17 \\
\hline \multicolumn{2}{|l|}{ Mitotic index } \\
\hline$\leq 5$ & 49 \\
\hline$>5$ & 14 \\
\hline \multicolumn{2}{|l|}{ Ki-67 } \\
\hline$\leq 5$ & 49 \\
\hline$>5$ & 14 \\
\hline \multicolumn{2}{|l|}{ CD117 } \\
\hline Positive & 61 \\
\hline Negative & 2 \\
\hline \multicolumn{2}{|l|}{ DOG-1 } \\
\hline Positive & 61 \\
\hline Negative & 2 \\
\hline \multicolumn{2}{|l|}{ CD34 } \\
\hline Positive & 62 \\
\hline Negative & 1 \\
\hline \multicolumn{2}{|l|}{ Gene mutation } \\
\hline KIT exon 11 & 47 \\
\hline KIT exon 9 & 3 \\
\hline KIT exon 13 & 1 \\
\hline KIT exon 17 & 1 \\
\hline PDGFRA exon 12 & 0 \\
\hline PDGFRA exon 18 & 1 \\
\hline Wild type & 10 \\
\hline
\end{tabular}

gastric GISTs $(P<0.05)$. The ratio of mitotic index $(>5$ per $50 \mathrm{HPF}$ ) was highest in the GISTs located in the cardia $(50 \%)$ and lowest in the gastric body (8\%). No GIST was found in the gastric antrum in our present study. Although the ratio of mitotic index ( $>5$ per $50 \mathrm{HPF}$ ) of gastric GISTs between 1 to $2 \mathrm{~cm}$ was higher than that of gastric GISTs less than $1 \mathrm{~cm}$ (33.33\% versus $12.12 \%)$, there was no significant difference between the two groups.
Table 2 The relationship between mitotic activity and clinical features

\begin{tabular}{lccc}
\hline Characteristics & \multicolumn{2}{c}{ Mitotic index } & Statistics \\
\hline Age & $\leq 5$ & $>5$ & \\
$\leq 50$ & 7 & 1 & $P=0.1400$ \\
51 to 60 & 8 & 4 & \\
61 to 70 & 27 & 4 & \\
$>70$ & 7 & 5 & $P=0.7591$ \\
Sex & & & \\
Male & 31 & 8 & \\
Female & 18 & 6 & \\
Tumor size & & & \\
$\quad \leq 1$ cm & 29 & 4 & \\
1 to 2 cm & 20 & 10 & \\
Tumor location & & & \\
$\quad$ Cardia & 4 & 4 & $P=0.0678$ \\
Gastric fundus & 20 & 8 & \\
Gastric body & 25 & 2 & \\
Clinical symptoms & & 2 & \\
Symptomatic & 34 & 15 & \\
Asymptomatic & 15 & & \\
\hline
\end{tabular}

McNemar's test and the Kappa test were used to measure the agreement between mitotic index and expression of Ki-67 of small gastric GISTs. The results in Table 3 show a good consistency between mitotic index and Ki-67 expression $(P=1.0000$, Kappa $=0.724)$.

\section{Discussion}

The management of GISTs is generally based on tumor size because biopsy is not recommended and mitotic index cannot be easily and accurately determined [13]. The National Comprehensive Cancer Network recommends surgical resection for tumors greater than $2 \mathrm{~cm}$ because of malignant potential, and lesions less than $2 \mathrm{~cm}$ can be conservatively followed up [14]. As a result, the malignant potential of small gastric GISTs could not be accurately determined due to the lack of mitotic index based on pathology. However, every GIST is now regarded as potentially malignant, and even GISTs with low mitotic rates were reported to recur locally or to metastasize [15]. The present study sought to identify the clinical and pathological features of

Table 3 The consistency of mitotic index and Ki-67 expression of small gastric gastrointestinal stromal tumors (GISTs)

\begin{tabular}{lllll}
\hline & & \multicolumn{2}{c}{ Ki-67 } & Statistics \\
\cline { 3 - 4 } & & $\mathbf{5 5}$ & $\mathbf{> 5}$ & \\
\hline Mitotic index & $\leq 5$ & 46 & 3 & $P=1.0000$ \\
& $>5$ & 3 & 11 & Kappa $=0.724$ \\
\hline
\end{tabular}


small gastric GISTs and to discuss the treatment strategy of small gastric GSITs.

As a specific marker of GISTs, CD117 has good sensitivity and was highly expressed in nearly $85 \%$ to $94 \%$ of cases [16]. The high sensitivity and specificity of CD117 is a useful marker in differentiating GIST from other mesenchymal tumors of the gastrointestinal tract. DOG1 (Discovered on GIST-1) is a newly identified marker of GISTs, West et al. reported ubiquitous expression of DOG-1 in GISTs and demonstrated the immunoreactivity for DOG-1 in $97.8 \%$ of GISTs [17]. Many reports showed that the sensitivity for CD117 and DOG1 are almost the same, and the two factors have consistency. As a hematopoietic progenitor cell antigen, CD34 is commonly present in GISTs but is less specific than CD117 and DOG1. The positive rate of CD34 is approximately $60 \%$ to $70 \%$ [18]. In our present study, the clinical and pathological characteristics of small gastric GISTs were in agreement with the references reported. These indicate that there is no significant difference in the clinical and pathological features between the small gastric GISTs in our study and the GISTs reported previously.

Tumor size and mitotic index are the best prognostic indicators for determining the malignant potential of GISTs [19]. In our present study, although all the gastric GISTs were less than $2 \mathrm{~cm}$, the mitotic index of 14 small gastric GISTs was greater than 5 per $50 \mathrm{HPF}$. It was striking to observe that $22.22 \%$ of small gastric GISTs showed low risk, which indicated the malignant potential and implied the necessity of surgical resection of small gastric GISTs. Furthermore, we analyzed the relationship between tumor size $(\leq 1 \mathrm{~cm}$ versus 1 to $2 \mathrm{~cm}$ ) and mitotic index. We found that there was no significant difference between the two groups, and the mitotic index of 4 out of 33 gastric GISTs $(\leq 1 \mathrm{~cm})$ was greater than 5 per $50 \mathrm{HPF}$. In this situation, we think that all GISTs should be resected once diagnosed. Besides tumor size and mitotic index, the location of GIST is also considered as one of the risk factors. It is reported that the location of GISTs in the gastric cardia and gastroesophageal junction is an unfavorable prognostic factor [20]. In our present study, 8 gastric GISTs were located in the gastric cardia, and the mitotic index of 4 cases exceeded 5 , demonstrating that GISTs located in the gastric cardia possess more malignant potential than those located in the gastric fundus and gastric body.

The current management policy for gastric GISTs less than $2 \mathrm{~cm}$ is usually conservative, unless tumors grow or symptoms occur [21]. In our present study, 46 of 63 cases (73.02\%) were presented with symptoms including pain, bleeding and discomfort. The high rate of presenting symptoms resulted from the combination of gastric cancer and gastric GIST of patients in our study. Even in the remaining 17 asymptomatic patients, the mitotic index of 2 cases was more than 5 per $50 \mathrm{HPF}$, indicating malignant potential. These findings also indicate that gastric GISTs less than 2 $\mathrm{cm}$ should be resected once diagnosed because most of the small gastric GISTs presented with symptoms, and some asymptomatic cases possessed malignant potential.

In 1998, Hirota et al. reported their groundbreaking discovery of KIT mutations in GISTs. It is now established that $70 \%$ to $80 \%$ of GISTs harbor a KIT gene mutation [22]. Most of these are exon 11 mutations, which cause constitutively activated receptors leading to unregulated autophosphorylation of the intracytoplasmic tyrosine kinases [23]. KIT mutations in exons 9, 13 and 17 are less common and have been associated with more aggressive tumor behavior [20]. PDGFRA mutations occur in approximately $20 \%$ to $25 \%$ of gastric GISTs, and most commonly in exon 18 [24]. KIT and PDGFRA mutations are mutually exclusive [25]. Very rare cases may have mutations in the BRAF kinase [26]. GISTs without a mutation in either KIT or PDGFRA genes account for about $10 \%$ to $15 \%$ of GISTs and are known as wild type [27]. In our present study, $74.60 \%$ of small gastric GISTs harbor a KIT exon 11 mutation, 4 cases $(4.76 \%)$ harbor a KIT exon 9 mutation, one case $(1.59 \%)$ harbors a KIT exon 13 mutation and one case $(1.59 \%)$ harbors a KIT exon 17 mutation. One case (1.59\%) harbors a PDGFRA exon 18 mutation, and 10 cases (15.87\%) were wild type. These results demonstrate that the gene mutation spectrum of small gastric GISTs in our present study is in agreement with the references reported.

Some authors have proposed the use of Ki-67 as a more objective parameter for risk assessment, because multivariate analyses in several studies do indicate that Ki-67 index could be independently used as an outcome predictor [28]. In our present study, the consistency of the mitotic index and Ki-67 expression was analyzed using McNemar's test and the Kappa test. The results showed a good consistency between mitotic index and Ki-67 expression. This indicated that Ki-67 expression may also be considered as a prognostic indicator for determining the malignant potential of gastric GISTs.

There are several limitations in the present study. First, no recurrence-free survival rate of patients who received surgical resection of small gastric GISTs could be obtained. Second, further studies should be carried out to investigate the necessity of medication after surgical resection. Third, multicenter randomized controlled studies should be carried out to confirm the benefit of surgical resection of small gastric GISTs compared with conservative patients.

\section{Conclusions}

Through pathological examination and gene mutation analysis, we found that some gastric GISTs less than $2 \mathrm{~cm}$ also harbor malignant potential, and recommend surgical resection of all small gastric GISTs once diagnosed. Thus, 
the treatment principle of gastric GISTs less than $2 \mathrm{~cm}$ should be reconsidered.

\section{Abbreviations}

CT: Enhanced abdominal computed tomography; DOG1: Discovered on GIST-1; EUS: Endoscopic ultrasound; GIST: Gastrointestinal stromal tumor; HPF: High-power fields; NCCN: National Comprehensive Cancer Network.

\section{Competing interests}

The authors declared that they have no competing interests.

\section{Authors' contributions}

YJJ designed the study; FF participated in data analysis; LMB carried out the operation; SL participated in acquisition of data; HL participated in immunohistochemisty; CL participated in gene mutation detection; WWB helped to draft the manuscript; XGH performed the statistical analysis; and ZHW, as director of the department, coordinated its execution and design, and drafted and produced the final version of the manuscript. All authors reviewed and approved the final manuscript.

\section{Acknowledgements}

Supported by grants from the National Natural Scientific Foundation of China (NO. 31100643 ).

Received: 25 June 2013 Accepted: 27 September 2013

Published: 13 October 2013

\section{References}

1. Grignol VP, Termuhlen PM: Gastrointestinal stromal tumor surgery and adjuvant therapy. Surg Clin North Am 2011, 91:1079-1087.

2. Hirota S, Isozaki K, Moriyama Y, Hashimoto K, Nishida T, Ishiguro S, Kawano K, Hanada M, Kurata A, Takeda M, Muhammad Tunio G, Matsuzawa Y, Kanakura Y, Shinomura Y, Kitamura Y: Gain-of-function mutations of c-kit in human gastrointestinal stromal tumors. Science 1998, 279:577-580.

3. Miettinen M, Lasota J: Gastrointestinal stromal tumors: review on morphology, molecular pathology, prognosis, and differential diagnosis. Arch Pathol Lab Med 2006, 130:1466-1478.

4. Agaimy A, Wang LM, Eck M, Haller F, Chetty R: Loss of DOG-1 expression associated with shift from spindled to epithelioid morphology in gastric gastrointestinal stromal tumors with KIT and platelet-derived growth factor receptor a mutations. Ann Diagn Pathol 2013, 17:187-191.

5. De Vogelaere K, Van Loo I, Peters O, Hoorens A, Haentjens P, Delvaux G: Laparoscopic resection of gastric gastrointestinal stromal tumors (GIST) is safe and effective, irrespective of tumor size. Surg Endosc 2012, 26:2339-2345

6. Casella C, Villanacci V, D'Adda F, Codazzi M, Salerni B: Primary extragastrointestinal stromal tumor of retroperitoneum. Clin Med Insights Oncol 2012, 6:189-197.

7. Maor Y, Avidan B, Melzer E, Bar-Meir S: Long-term clinical outcome of patients with gastric gastrointestinal stromal tumors. Dig Dis Sci 2010, 55:2893-2898

8. von Mehren M, Benjamin RS, Bui MM, Casper ES, Conrad EU 3rd, DeLaney TF, Ganjoo KN, George S, Gonzalez R, Heslin MJ, Kane JM 3rd, Mayerson J, McGarry SV, Meyer C, O'Donnell RJ, Paz B, Pfeifer JD, Pollock RE, Randall RL, Riedel RF, Schuetze S, Schupak KD, Schwartz HS, Shankar S, Van Tine BA, Wayne J, Sundar H, McMillian NR: Soft tissue sarcoma, version 2.2012: featured updates to the NCCN guidelines. J Natl Compr Canc Netw 2012, 10:951-960

9. Lai IR, Chen CN, Lin MT, Lee PH: Surgical treatment of gastric gastrointestinal stromal tumors: analysis of 92 operated patients. Dig Surg 2008, 25:208-212.

10. Demetri $G D$, Benjamin RS, Blanke CD, Blay JY, Casali P, Choi H, Corless $C L$, Debiec-Rychter M, DeMatteo RP, Ettinger DS, Fisher GA, Fletcher CD, Gronchi A, Hohenberger P, Hughes M, Joensuu H, Judson I, Le Cesne A, Maki RG, Morse M, Pappo AS, Pisters PW, Raut CP, Reichardt P, Tyler DS, van den Abbeele AD, von Mehren M, Wayne JD, Zalcberg J, NCCN Task Force: NCCN Task Force report: management of patients with gastrointestinal stromal tumor (GIST)-update of the NCCN clinical practice guidelines. J Natl Compr Canc Netw 2007, 5(Suppl 2):S1-S29. quiz S30.

11. Casali PG, Jost L, Reichardt P, Schlemmer M, Blay JY, ESMO Guidelines Working Group: Gastrointestinal stromal tumours: ESMO clinical recommendations for diagnosis, treatment and follow-up. Ann Oncol 2009, 20(Suppl 4):64-67.

12. Melstrom LG, Phillips JD, Bentrem DJ, Wayne JD: Laparoscopic versus open resection of gastric gastrointestinal stromal tumors. Am J Clin Oncol 2012, 35:451-454.

13. Kim MY, Park YS, Choi KD, Lee JH, Choi KS, Kim do H, Song HJ, Lee GH, Jung HY, Kim JH, Yun SC, Kim KC, Yook JH, Oh ST, Kim BS, Ryu MH, Kang YK: Predictors of recurrence after resection of small gastric gastrointestinal stromal tumors of $5 \mathrm{~cm}$ or less. J Clin Gastroenterol 2012, 46:130.

14. Demetri GD, von Mehren M, Antonescu CR, DeMatteo RP, Ganjoo KN, Maki RG, Pisters PW, Raut CP, Riedel RF, Schuetze S, Sundar HM, Trent JC, Wayne JD: NCCN Task Force report: update on the management of patients with gastrointestinal stromal tumors. I Nat/ Compr Canc Netw 2010, 8(Suppl 2):S1-S41. quiz S42-44

15. Corless CL, McGreevey L, Haley A, Town A, Heinrich MC: KIT mutations are common in incidental gastrointestinal stromal tumors one centimeter or less in size. Am J Pathol 2002, 160:1567-1572.

16. Sui XL, Wang H, Sun XW: Expression of DOG1, CD117 and PDGFRA in gastrointestinal stromal tumors and correlations with clinicopathology. Asian Pac J Cancer Prev 2012, 13:1389-1393.

17. West RB, Corless $\mathrm{CL}$, Chen $\mathrm{X}$, Rubin BP, Subramanian S, Montgomery K, Zhu $S$, Ball CA, Nielsen TO, Patel R, Goldblum JR, Brown PO, Heinrich MC, van de Rijn M: The novel marker, DOG1, is expressed ubiquitously in gastrointestinal stromal tumors irrespective of KIT or PDGFRA mutation status. Am J Pathol 2004, 165:107-113.

18. Lai EC, Lau SH, Lau WY: Current management of gastrointestinal stromal tumors-a comprehensive review. Int J Surg 2012, 10:334-340.

19. Dematteo RP, Gold JS, Saran L, Gönen M, Liau KH, Maki RG, Singer S, Besmer P, Brennan MF, Antonescu CR: Tumor mitotic rate, size, and location independently predict recurrence after resection of primary gastrointestinal stromal tumor (GIST). Cancer 2008, 112:608-615.

20. Roggin KK, Posner MC: Modern treatment of gastric gastrointestinal stromal tumors. World J Gastroenterol 2012, 18:6720-6728.

21. Fujimoto A, Kobayashi T, Uchida S, Ichinose Y, Sasaoki T, Goto K, Okabe H Laparoscopic total gastrectomy for multiple sporadic gastric gastrointestinal stromal tumors: report of a case. Surg Today 2012, 42:84-88.

22. Corless $\mathrm{CL}$, Barnett $\mathrm{CM}$, Heinrich MC: Gastrointestinal stromal tumours: origin and molecular oncology. Nat Rev Cancer 2011, 11:865-878.

23. Miettinen M, Lasota J: Histopathology of gastrointestinal stromal tumor. J Surg Oncol 2011, 104:865-873.

24. Lasota J, Miettinen M: Clinical significance of oncogenic KIT and PDGFRA mutations in gastrointestinal stromal tumours. Histopathology 2008, 53:245-266

25. Heinrich MC, Corless CL, Duensing A, McGreevey L, Chen CJ, Joseph N Singer S, Griffith DJ, Haley A, Town A, Demetri GD, Fletcher CD, Fletcher JA: PDGFRA activating mutations in gastrointestinal stromal tumors. Science 2003, 299:708-710.

26. Hostein I, Faur N, Primois C, Boury F, Denard J, Emile JF, Bringuier PP, Scoazec JY, Coindre JM: BRAF mutation status in gastrointestinal stromal tumors. Am J Clin Pathol 2010, 133:141-148.

27. Liegl-Atzwanger B, Fletcher JA, Fletcher CD: Gastrointestinal stromal tumors. Virchows Arch 2010, 456:111-127.

28. Patil DT, Rubin BP: Gastrointestinal stromal tumor: advances in diagnosis and management. Arch Pathol Lab Med 2011, 135:1298-1310.

doi:10.1186/1477-7819-11-273

Cite this article as: Yang et al.: Surgical resection should be taken into consideration for the treatment of small gastric gastrointestinal stromal tumors. World Journal of Surgical Oncology 2013 11:273. 